\title{
NEUROPROTECTIVE EFFECT OF GREWIA CARPINIFOLIA EXTRACT AGAINST VANADIUM INDUCED BEHAVIOURAL IMPAIRMENT
}

\author{
Adebiyi, O. E. ${ }^{1}$, Olopade J. O. ${ }^{2}$, Olayemi, F. O. ${ }^{1}$ \\ ${ }^{1}$ Department of Veterinary Physiology, Biochemistry and Pharmacology \\ ${ }^{2}$ Department of Veterinary Anatomy, University of Ibadan \\ Nigeria
}

olamideadebiyi2015@yahoo.com

\section{ABSTRACT}

Vanadium (V), a heavy metal, has been reported to induce central nervous system toxicity leading to various behavioural impairments. It is characterized by the production of reactive oxygen. The present study was designed to test the possibility of Grewia carpinifolia ethanolic extract in preventing behavioural alterations following acute vanadium toxicity in mice. Twenty five Swiss albino mice $(25-27 \mathrm{~g})$ were completely randomized into 5 groups $(\mathrm{A}-\mathrm{E})$ of 5 animals each. Group A received distilled water and served as a control; group $B$, received vitamin $E$ ( $500 \mathrm{mg} . \mathrm{kg}^{-1}$ b.w. every 72 hours), a known antioxidant orally, along with a daily dose of sodium metavanadate intraperitoneally (i.p.) for 7 days; group C and group D received Grewia carpinifolia leaf extract at 100 and $200 \mathrm{mg} \cdot \mathrm{kg}^{-1}$ b.w orally respectively, along with the sodium metavanadate i.p. for 7 days; while group E received sodium metavanadate i.p. only for 7 days. The behavioural and motor functions were analysed by the open field, negative geotaxis, and hanging wire tests; the daily body and brain weights were recorded. Grewia carpinifolia ethanolic extracts significantly reduced the number of grooming, stretched attend posture, and freezing time that were significantly increased in the vanadium only group and also enhanced the vestibular functions. In addition, the latent time spent on the hanging wire in groups simultaneously administered with the extract and $\mathrm{V}$ compared favourably $(P>0.05)$ with the control groups but a decrease in latent time was observed in the $\mathrm{V}$ only group. The results suggest that acute $\mathrm{V}$ toxicity results in various behavioural deficits and support a possible role of Grewia carpinifolia as a protective agent against acute vanadium-toxicity with a better result at $200 \mathrm{mg} \cdot \mathrm{kg}^{-1}$ b. w.

Key words: behaviour; Grewia carpinifolia; mice; vanadium

\section{INTRODUCTION}

Vanadium is a trace element that is widely distributed in nature. Power- and heat-producing industrial plants us- 
ing fossil fuels (petroleum, coal, oil) cause the most widespread discharge of vanadium into the environment. The incidence of exposure to toxic levels of vanadium to industrial workers has been of increasing concern [21, 24]. Environmental exposure occurs via inhalation in the surrounding area of metallurgical plants or through the consumption of contaminated foods $[4,24,25]$, and recently from massive oil burning, as seen in Arabian Gulf [6], the Niger-Delta region of Nigeria [20], and the Gulf of Mexico. The mangrove forest of the Niger-Delta of Nigeria, covering about $70000 \mathrm{~km}^{2}$ of wetlands (the largest in Africa and the third largest in the world) with a population of about 20 million has been the centre of constant exploration for oil by many international oil companies [44]. These exploratory activities often lead to gas flaring and oil spillage impacting negatively on the aquatic and terrestrial habitats, as well as animal and human health [22].

Vanadium compounds have been reported to cause toxic effects by most routes of exposure in most species [14]. The disposition of vanadium in specific tissues may be involved in the pathogenesis of certain neurological disorders and cardiovascular diseases [46]. Its capacity to affect the activities of various other intracellular enzyme systems and modify physiological processes damaging cell membrane via the production of free radical has also been documented [6]. The central nervous system (CNS); rich in polyunsaturated fatty acid side chains, with high oxygen tension but poor in antioxidant capacity, is very vulnerable to free radical damage [1] by vanadium leading to: tremors, CNS depression and various behavioural alterations [44]. Several investigators have demonstrated that antioxidants such as $a$-tocopherol and ascorbic acid protect the brain against vanadium-induced (ree radical injury [13, 33]. Consequently, some medicinal plants have been reported to contain some phytochemicals, mostly polyphenols and flavonoids, which exhibit high antioxidant activity [16]. Furthermore, natural sources of antioxidants have been severally studied in a bid to discover potentially safer, effective, and cheaper antioxidants $[5,28,36]$. Therefore, there is a need for the study of plants that may offer some protection against the effects of vanadium in a country such as Nigeria which is known for oil spillage and gas flaring where about $61 \%$ of its citizen are impoverished and cannot readily afford conventional drugs [31].

Most species in the genus, Grewia have been reported to have antioxidant properties and are used in the treat- ment of various disorders in man and other animals [17]. Triterpenoids, steroids, glycosides, flavones, lignans, phenolics, alkaloids, lactones, anthocyanins, flavones, and organic acids have been isolated from various species of this genus [27, 34].

To this end, this study was designed to investigate the hypothesis that a nutritional strategy like co-administration of ethanolic extract of G. carpinifolia leaves could ameliorate vanadium-induced neurotoxicity in mice.

\section{MATERIALS AND METHODS}

\section{Experimental animals}

Twenty five male mice weighing between $25-27 \mathrm{~g}$ were randomly divided into five groups $(\mathrm{A}-\mathrm{E})$ of five animals per group. They were obtained and kept in the experimental animal house of the Department of Veterinary Physiology, Biochemistry and Pharmacology, University of Ibadan. The animals were 5 weeks old and housed under standard conditions of temperature, $\left(25 \pm 2{ }^{\circ} \mathrm{C}\right)$ and light, (approximately 12/12 h light-dark cycle), fed on standard diet (Animalcare ${ }^{\circledast}$ Feeds Ltd., Nigeria) with fresh water ad libitum. The cages were cleaned of waste daily. All the animals were acclimatized to the laboratory conditions for two weeks before the commencement of the experiments. The study was approved by the Animal Care and Use Research Ethics Committee, University of Ibadan (UI-ACUREC/App/2016/025).

\section{Plant material and extraction}

Fresh leaves of Grewia carpinifolia were collected from the Botanical Garden of the University of Ibadan. It was identified and authenticated at the Forestry Research Institute of Nigeria (FRIN) where herbarium specimen (voucher number FHI 109693) was deposited.

The plant sample $(5 \mathrm{~g})$ was homogenized in $80 \%$ aqueous ethanol at room temperature and centrifuged at $10,000 \mathrm{rpm}$ for $15 \mathrm{~min}$ and the supernatant was preserved. The residue was re-extracted twice with $80 \%$ ethanol and supernatants were pooled, put into evaporating dishes and evaporated to dryness at room temperature.

\section{Experimental design}

The experiment to determine the ameliorative effect of Grewia carpinifolia on white laboratory mice following 
acute vanadium intoxication was designed to span 8 days Group A received distilled water throughout the experimental period and served as a control; group B, the standard group received vitamin E (500 mg. $\left.\mathrm{kg}^{-1}\right)$ every $72 \mathrm{~h}$ orally along with a daily dose of sodium metavanadate (Sigma-Aldrich, St. Louis, USA) at $3 \mathrm{mg} \cdot \mathrm{kg}^{-1}$ [29] intraperitoneally (i.p.) for 7 days consecutively; group $\mathrm{C}$ and group D received Grewia carpinifolia leaf extract at a single daily dose of 100 and $200 \mathrm{mg} . \mathrm{kg}^{-1}$ orally respectively, along with sodium metavanadate at $3 \mathrm{mg} \cdot \mathrm{kg}^{-1}$ i. p. for 7 days consecutively; and group $\mathrm{E}$ received only sodium metavanadate at $3 \mathrm{mg} \cdot \mathrm{kg}^{-1}$ i.p. for 7 days consecutively. The present study was conducted in line with the European laws on the protection of animals (86/609/EEC). The protocols for the experiments were approved by the institutional animal care and ethics committee.

\section{Open field test}

Locomotor and exploratory activities were measured by an open-field task box (Coulbourn Instruments L. L. C., PA, USA). Each animal was placed individually at the centre of the apparatus and observed for 5 minutes to record the movement time, length and number of line crossing and time spent (exploratory activity) at the centre of the open field box by TruScan software v 2.07 (Coulbourn Instruments L. L. C., PA, USA)

The following observations as previously described by B rown et al., [10] were also recorded:

(A)Line crossing: number of times a mouse crossed from one square to another with at least its two front paws.

(B) Rearing: number of times mouse stood on its hind legs.

(C) Grooming: sets of heterogeneous components comprising face washing, body licking, paw licking, head and body shaking, scratching and genital licking while stationary.

(D)Stretched attend posture: duration of time the mouse stood still with forward elongation of the head and shoulders.

(E) Time spent at the centre, duration of time the mouse spent at the centre square.

(F) Freezing: duration with which the mouse was completely stationary.

The open field box was cleaned with methylated spirit before placing the subsequent animals in it in order to avoid possible bias effects due to odour clues left by a previous mouse.

\section{Fore limb support (hanging wire) test}

This test is based on the latency of a mouse to fall off a metal wire upon exhaustion based on the method described by Van Putten et al. [45]. A 2 mm thick metallic wire secured to two vertical stands was used. The wire was tightly attached to the frame to avoid vibration or unwanted displacement of the wire during the measurements. Each mouse was placed on the wire with its fore limb and monitored for a maximum period of 120 seconds. The period of time it took the animal to stay on the wire before falling was taken and recorded $[9,11]$. The animals that did not fall off the hanging wire during the test period of 120 seconds were given a maximum score [30].

\section{Negative geotaxis test}

Each animal was placed in the middle of a board, 300 inclined to the surface plane, in a head-down position and the latency to turn and orient its position; to be facing up the slope, is recorded [8].

Two trials were performed for each mouse in both the hanging wire and negative geotaxis tests. The second trial was done 3 to 4 hours after the completion of the first trial; hence all mice were well rested before the second trial.

\section{Body weight}

Rats in all the groups were weighed daily throughout the experiment.

\section{Relative brain weight (RBW)}

Rats were anesthetized with ketamine following which the frontal, parietal and temporal bones were gently removed to expose the brain which was carefully removed, weighed and observed macroscopically [47]. The relative brain weight of each rat was calculated as follows:

$$
\mathrm{RBW}=\frac{\text { Absolute organ weight }(\mathrm{g})}{\text { Body weight of rats on sacrifice day }(\mathrm{g})}
$$

\section{Statistical analysis}

The results were analysed using the statistical package GraphPad prism version 5.01 (San Diego, USA). These data were subjected to one-way ANOVA and subsequently to the Bonferroni post-test to perform multiple comparisons in order to assess the statistical significance of differences between all possible pairs of groups. Repeated measures 
on the same animals were analysed using the Wilcoxon matched-pair, signed-rank test [41]. Differences were regarded as statistically significant when $\mathrm{P}<0.05$.

\section{RESULTS}

\section{Open field test}

The mean values for observations of the Open field test in the experimental animals are presented (Table 1 ). A statistically significant $(\mathrm{P}<0.05)$ decrease was observed in the number of line crossing in the group administered with $100 \mathrm{mg} \cdot \mathrm{kg}^{-1}$ of the extract (group C) and the vanadium group (E) when compared with the control and other test groups. There was also a significant increase $(\mathrm{P}<0.05)$ in the number of rearing in the group administered with only vanadium (E); however, there was no difference in these parameters in the other test groups when compared with the control. The time spent at the centre of the open field after seven days co-administration of ethanolic extract of Grewia carpinifolia at $200 \mathrm{mg} . \mathrm{kg}^{-1}$ p.o. with vanadium (group D) was not significantly different from those of the control and the standard group administered with vitamin E; conversely a significant increase in time spent at the centre of the box was recorded in the vanadium only group (E) when compared with the other groups.

\section{Hanging wire test}

The extract treated groups (C and D) spent more time on the hanging wire before falling off, although this was of no significant difference $(\mathrm{P}>0.05)$ when compared to the control group; however, vanadium at $3 \mathrm{mg} \cdot \mathrm{kg}^{-1}$ resulted in a statistically significant $(\mathrm{P}<0.05)$ decrease in the time spent on the hanging wire test (Figure 1). Two trials were performed for each mouse. The second trial was done after all the animals had successfully completed the first trial; hence all mice were well rested before the second trial.

\section{Negative geotaxis test}

The mean time for negative geotaxis of the vanadium only group $(\mathrm{E})$ was statistically $(\mathrm{P}<0.05)$ higher than those of the extract at tested doses and the standard drug (Figure 2).

\section{Body weight}

An increase in daily body was observed in all the groups from day 1 to day 5. There was a decrease in body weight in groups B-E on day 6, after which daily weight gain resumed in groups B-D on day 7 and 8; however the daily body weight continued to decrease in group $\mathrm{E}$ after day 6 .

\section{Relative brain weight}

There was no significant difference $(P>0.05)$ in the relative brain weight of the animal across all the groups (Table 2).

\section{DISCUSSION}

Vanadium (V) is a pro-oxidant and indirectly results in the production of free radicals leading to oxidative damage $[6,12]$ and the possible role of vanadium in behavioural changes has been studied [32]. Vanadium (V) crosses the blood brain barrier and possibly alters the biochemistry of the brain of treated animals [18]. The central nervous system (CNS) myelin could be a preferential target of vanadium mediated lipid peroxidation in rats and mice since the brain has a high metabolic activity as well as a high concentration of myelin [26]. This may consequently increase the susceptibility of the nervous tissue to peroxidative damage $[15,39]$ by $\mathrm{V}$ which causes behavioural alterations.

Behavioural studies can be used in risk assessment following neurotoxicity as it represent the net output of the sensory, motor and cognitive functions occurring in the nervous system [33].

The Open field test is one of the most commonly used tests in animal behavioural studies [40]. In the present study, the number of rearing and grooming was significantly increased after vanadium exposure in the Open field test which may indicate an increase in anxiety in the vanadium only treated when compared to the control animals as well as the extract treated groups. The locomotion was also reduced in the vanadium treated group as indicated by an increase in time spent at the centre of the open field maze, as well as a reduction in the number of new square crossing. The extract at $200 \mathrm{mg} \cdot \mathrm{kg}^{-1}$ conversely had values comparable with the control and standard group; this may be linked to the ability of the extract at this dosage to reduce or eliminate anxiety-like behaviours in vanadium exposed mice.

Stretched attend posture (SAP) is an essential component of risk-assessment defensive behaviour in rodents [7]. The mice exposed to vanadium in this study, unlike 
Table 1. The mean values for observations of the Open field test $($ mean $\pm S D)$

\begin{tabular}{|c|c|c|c|c|c|}
\hline Observation & $\begin{array}{l}\text { Group A } \\
\text { (Control) }\end{array}$ & $\begin{array}{l}\text { Group B } \\
(V+\text { vit. E) }\end{array}$ & $\begin{array}{c}\text { Group C } \\
(\mathrm{V}+\text { G. carpinifolia } \\
\left.\text { at } 100 \mathrm{mg} \cdot \mathrm{kg}^{-1}\right)\end{array}$ & $\begin{array}{c}\text { Group D } \\
(\mathrm{V}+\mathrm{G} \text {. carpinifolia at } \\
\left.200 \mathrm{mg} \cdot \mathrm{kg}^{-1}\right)\end{array}$ & $\begin{array}{l}\text { Group E } \\
\text { (V only) }\end{array}$ \\
\hline Line crossing & $55.64 \pm 27.29$ & $59.00 \pm 2.53$ & $24.00 \pm 16.15^{*}$ & $59.00 \pm 5.93$ & $18.60 \pm 4.67^{*}$ \\
\hline Rearing & $17.67 \pm 13.50$ & $13.00 \pm 1.41$ & $3.25 \pm 1.89^{*}$ & $10.00 \pm 1.82$ & $73.25 \pm 7.23^{*}$ \\
\hline $\begin{array}{l}\text { Grooming } \\
\text { [sec] }\end{array}$ & $21.33 \pm 11.85$ & $16.00 \pm 11.31$ & $12.00 \pm 4.69$ & $21.65 \pm 4.72$ & $14.40 \pm 7.33$ \\
\hline $\begin{array}{l}\text { Stretched attend posture } \\
\text { [sec] }\end{array}$ & $34.36 \pm 4.09$ & $38.60 \pm 5.02$ & $36.08 \pm 7.32$ & $35.21 \pm 2.58$ & $62.09 \pm 10.36^{*}$ \\
\hline $\begin{array}{l}\text { Time spent at the centre } \\
\text { [sec] }\end{array}$ & $2.54 \pm 0.03$ & $2.86 \pm 0.83$ & $3.81 \pm 0.51$ & $3.00 \pm 0.12$ & $22.64 \pm 10.40^{*}$ \\
\hline $\begin{array}{l}\text { Freezing } \\
\text { [sec] }\end{array}$ & $110.08 \pm 9.06$ & $103 \pm 7.43$ & $98.21 \pm 7.65$ & $112 \pm 14.56$ & $135 \pm 13.48$ \\
\hline
\end{tabular}

SD - standard deviation; number of animals in the group $n=5$

* —statistically different from the control at $\mathrm{P}<0.05$

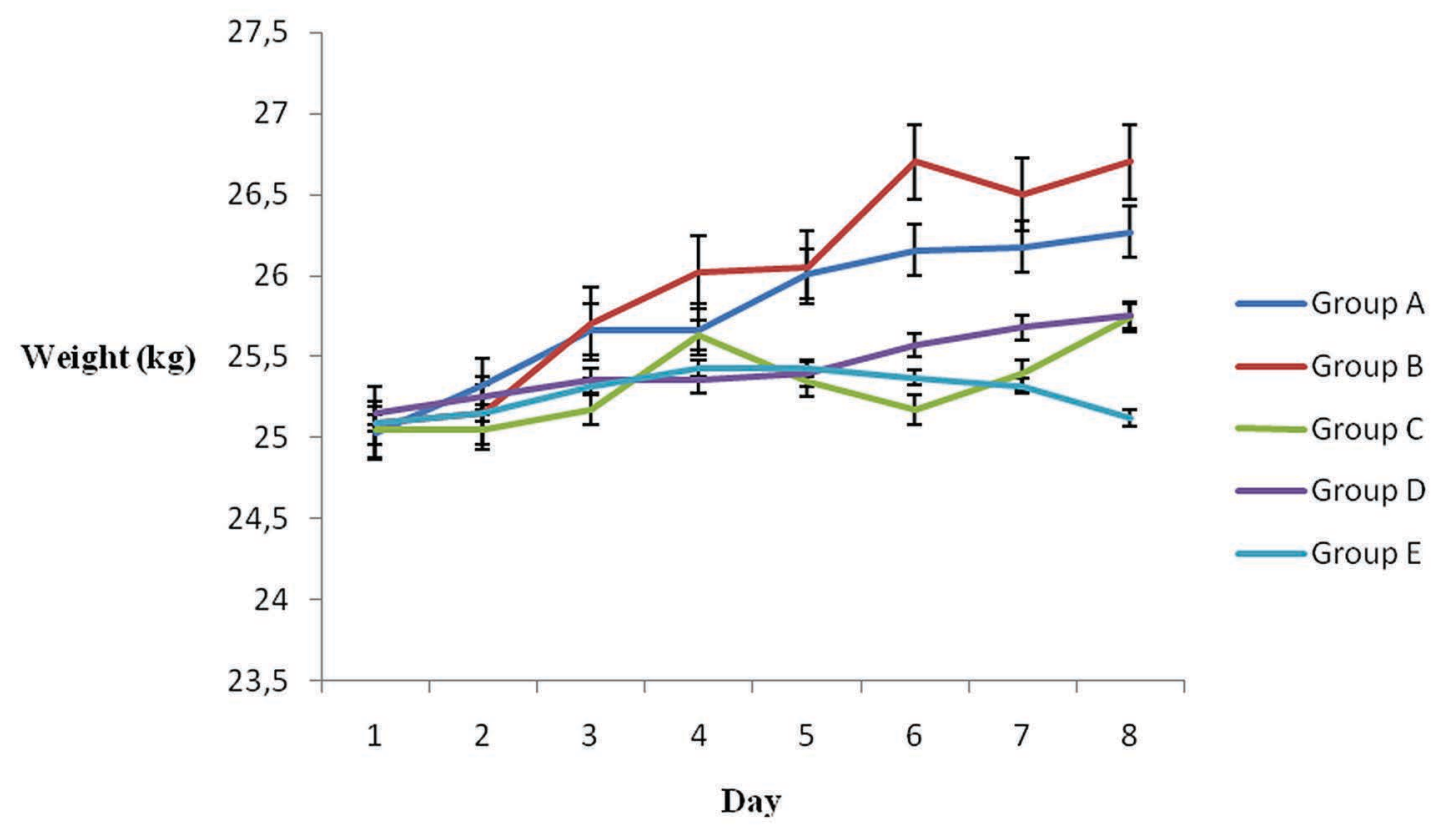

Fig. 1. Time spent on the hanging wire

* — statistically different from the control at $\mathrm{P}<0.05$ 


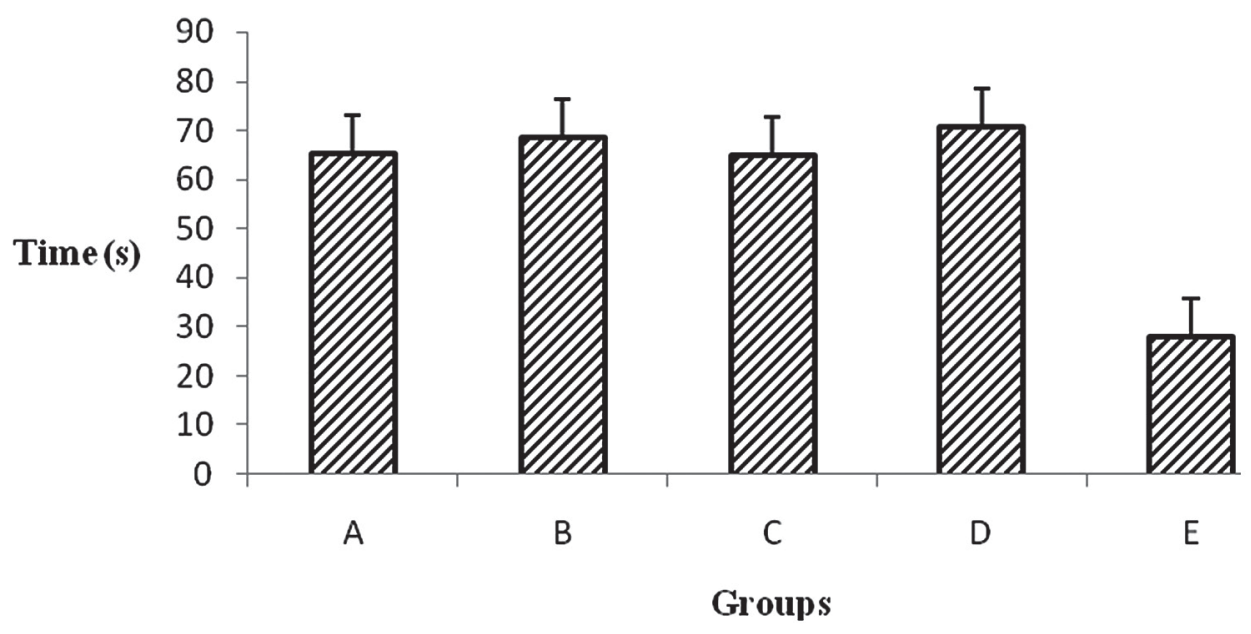

Fig. 2. Mean values for negative geotaxis of experimental animals

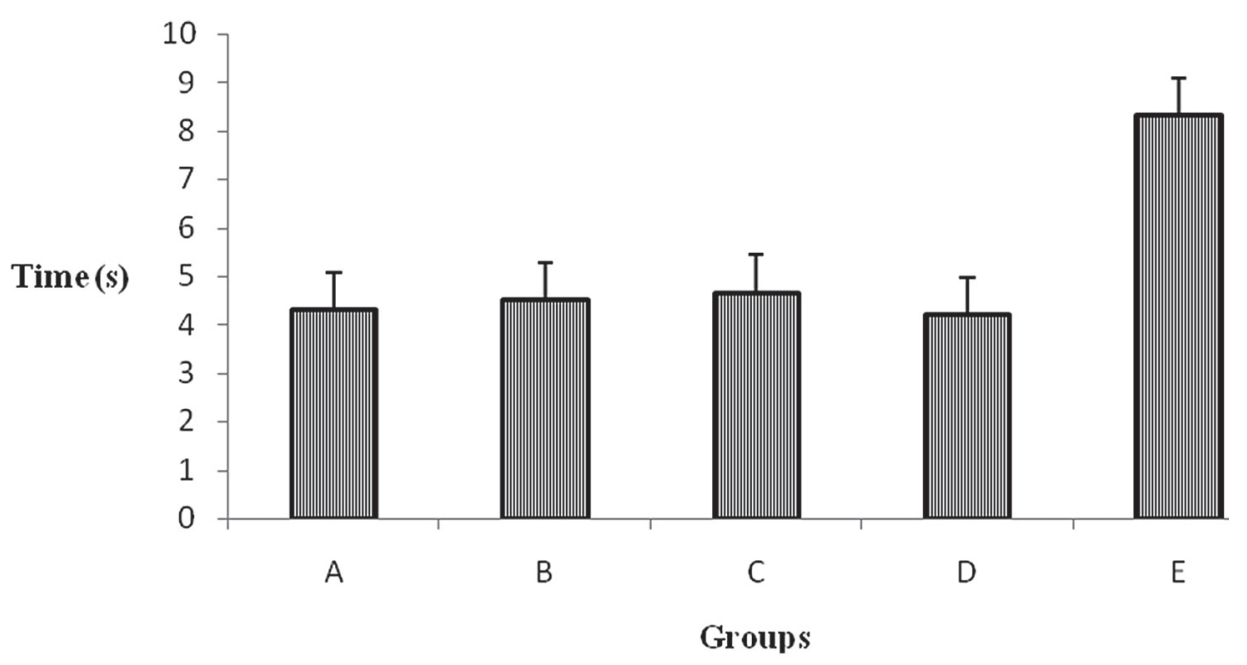

Fig. 3. Mean values for daily body weight

Table 2. Mean values for relative brain weight

\begin{tabular}{cc}
\hline Group & $\begin{array}{c}\text { Relative } \\
\text { Brain Weight }\left(\times \mathbf{1 0}^{-2}\right)\end{array}$ \\
\hline A & $5.34 \pm 0.17$ \\
B & $5.02 \pm 0.21$ \\
C & $5.20 \pm 0.22$ \\
D & $5.45 \pm 0.10$ \\
E & $5.14 \pm 0.23$ \\
\hline
\end{tabular}

the control and test groups, recorded a significant increase in stretched attend posture. This increase in stretched attend posture (SAP) may suggest anxiety of the mice, which has been indicated to result in low motivation to explore novelty which makes an animal take the stretch-attend posture. This is in concordance with results obtained by Mustapha [29], Soazo and Garcia [42] following vanadium intoxication. Furthermore, this hesitance by the vanadium treated group to move may be attributed to vanadium-induced muscular weakness [32]. In general, observations in the open field test were similar in the G. car- 
pinifolia extract treated and control groups in this study. Although, Pfau and Skog [35] had documented that the genus Grewia possess some anxiolytic activity, the mechanism by which the extract of G. carpinifolia reduced anxiety is still not certain.

In this study, muscular strength was found to be significantly decreased after vanadium treatment as observed in the hanging wire test. This finding highlights the fact that heavy metals have been implicated in muscles and joints pain [3] and further supports that $\mathrm{V}$ intoxication results in muscular weakness [32]. The present study may point to the fact that high levels of vanadium may interfere with motor functions leading to decreased motor activities, as well as grip strength in mice. However, the findings of this study also showed that concurrent administration of G. carpinifolia extract to V exposed animals proved beneficial as the animals performed better on the hanging wire test, as evidenced by an increase in the suspension time. The hanging wire test can be used to assess global sub-acute muscle function and coordination over time in mice [23] and the ability of the mice to produce sustained tension in the limb musculature. Thus, G. carpinifolia extract may have ameliorative effect on muscular weakness caused by $\mathrm{V}$ intoxication by improved muscle function and coordination in mice.

The negative geotaxis is a reflex test which reflects vestibular function, motor development and activity [2]. Vanadium has been reported to induce vestibular damage [29], and generally, mice with vestibular dysfunction become disoriented and unable to generally explore a novel setting [37]. This could explain the increased time in the negative geotaxis shown by the mice given vanadium only. Nevertheless, the similarities in the lower latent time of the extract treated group at $200 \mathrm{mg} \cdot \mathrm{kg}^{-1}$ and those of the control and standard group, further supports the neuroprotective activity of the plant extract at this dosage. This result of the negative geotaxis further substantiates the findings in the Open field test.

In this study, the daily body weights of the vanadium only exposed mice decreased continuously after the sixth day following the vanadium administration. The observed insignificant decrease (when compared with other test groups and control) in daily body weight observed in the present study is in consonance with the findings by Garcia et al., $[14,15]$ in acute vanadium toxicity in rats. Vanadium toxicity have been previously reported to induce anorexia [19] leading to the reduction in daily body weights which becomes significant following chronic exposure as reported by Sánchez et al. [38] and Todorich et al. [43]. The insignificant difference in relative brain weight in this study is in line with that observed by Garcia et al., [14] but contrary to that of Altamirano et al. [4] who had described a significant decrease in brain weight following vanadium toxicity, the variance in these results may be ascribed to the fact that six [6] weeks old mice were used in this study, while in their studies the mice were exposed at post-natal day one [1]. It seems that vanadium has more effect on brain weight when exposed to neonates undergoing a high degree of cellular proliferation.

Grewia carpinifolia extract contains numerous phytochemical constituents including: tannins, phlobatinins, saponin, flavonoids, terpenoids, cardiac glycosides, coumarin, alkaloids and anthraquinone [17]. Many of these compounds have proven their potential as antioxidants in various oxidative stress models as scavengers of free radicals as reported in prior studies [36]. The observed beneficial effects of $G$. carpinifolia extract in vanadium-induced changes in behaviour may thus be attributed to these diversified chemical components.

\section{CONCLUSIONS}

This study has shown that G. carpinifolia extract administered in combination with vanadium ameliorates vanadium induced behavioural impairments. The extract showed better protective activity at $200 \mathrm{mg} \cdot \mathrm{kg}^{-1}$. Therefore, the plant should be given more emphasis as a candidate in developing a modern drug to minimise vanadium induced toxicity. Further study is on-going to isolate and characterize the bioactive principle(s) of the extract with the aim of determining its exact mechanism of action.

\section{REFERENCES}

1. Afeseh, N.H., Kanthasamy, A., Anantharam, V., Song, C., Witte, T., Houk, R.S., Kanthasamy, A. G., 2009: Vanadium induces dopaminergic neurotoxicity via protein kinase C-delta dependent oxidative signaling mechanisms: Relevance to etiopathogenesis of Parkinson's disease. Toxicol. Appl. Pharmacol., $240,273-285$. 
2. Alberts, J. R., Motz, B.A., Schank, J.C., 2004: Positive geotaxis in rats: a natural behavioural and an historical correction. J. Comp. Psychol., 118, 123-132.

3. Alloway, B. J., 2013: Heavy Metals in Soils: Environmental Pollution Series. 11th edn., Springer, 615 pp.

4. Altamirano, M., Alvarez, L., Roldan, E., 1993: Cytogenetic and teratogenic effects of vanadium pentoxide on mice. Medical Science and Research, 21, 1-3.

5. Amit Subedi, A., Amatya, M. P., Shrestha, T. M., Mishra, S. K., Pokhrel, B. M., 2012: Antioxidant and antibacterial activity of methanolic extract of Machilus odoratissima. KUSET, 8, 73-80. www.ku.edu.np/kuset/.

6. Avila-Costa, M.R., Fortoul, T.I., Niño-Cabrera, G., Colín-Barenque, L., Bizarro-Nevares, P., Gutiérrez-Valdez, A. L. et al., 2006: Hippocampal cell alterations induced by the inhalation of vanadium pentoxide promote memory deterioration. Neurotoxicology, 27, 1007-1012.

7. Blanchard, D.C., Griebel, G., Blanchard, R.J., 2001: Mouse defensive behaviours: pharmacological and behavioural assays for anxiety and panic. Neurosci. Biobehav. Rev., 25, 205-218.

8. Bouet, R. J., Wubbels, H. A., De Jong, A. G., 2004: Behavioural consequences of hyperactivity in developing rats. Brain Res. Dev. Brain Res., 153, 69-78.

9. Brooks, S.P., Dunnett, S.B., 2009: Tests to assess motor phenotype in mice: a user's guide. Nat. Rev. Neurosci., 10, 519-529.

10. Brown, R.E., Corey, S.C., Moore, A.K., 1999: Differences in measures of exploration and fear in MHC-congenic C57BL/6J and B6-H-2K mice. Behav. Genet., 26, 263-271.

11. Carlson, C. G., Rutter, J., Bledsoe, C., Singh, R., Hoff, H., Bruemmer, K. et al., 2010: A simple protocol for assessing inter-trial and inter-examiner reliability for two non-invasive measures of limb muscle strength. J. Neurosci. Methods, 186, $226-230$.

12. Conte, V., Floris, B., 2010: Review: Vanadium catalyzed oxidation with hydrogen peroxide. Inorg. Chim. Acta, 363, 1935-1946.

13. El-Shaari, F. A., Haider, S.S., El-Fakhri, M.M., Ghawarsha, K.M., 2002: Does ascorbic acid protect against vanadium neurotoxicity in different regions of rat brain? Neurosci., 7, $2-286$.

14. Garcia, G.B., Biancardi, M.E., Quiroga, A.D., 2005: Vanadium (V)-induced neurotoxicity in the rat central nervous system: a histo-immunohistochemical. Drug Chem. Toxicol., 28, 329-344.

15. Garcia, G. B., Quiroga, A. D., Sturtz, N., Martinez, A. I., Biancardi, M.E., 2004: Morphological alterations of central ner- vous system (CNS) myelin in vanadium (V)-exposed adult rats. Drug Chem. Toxicol., 27, 281-293.

16. Gohari, A. R., Hajimehdipoor, H., Saeidnia, S., Ajani, Y., Hadjiakhoondi, A., 2011: Antioxidant Activity of some Medicinal Species using FRAP Assay. Journal of Medicinal Plants, 10, $54-60$.

17. Goyal, P.K., 2012: Phytochemical and pharmacological properties of the genus Grewia: A review. International Journal of Pharmacy and Pharmaceutical Sciences, 4, 72-82.

18. Haider, S.S., Abel-Gayoumaa, A., El-Fakhri, M., Ghwarsha, K.M., 1998: Effect of selenium on vanadium toxicity in different regions of rat brain. Hum. Exp. Toxicol., 17, 23-28.

19. Hosseini, M., Seyedrazi, N., Shahraki, J., Pourahmad, J., 2012: Vanadium induces liver toxicity through reductive activation by glutathione and mitochondrial dysfunction. Advances in Bioscience and Biotechnology, 3, 1096-1103.

20. Igado, O. O., Olopade, J. O., Onwuka, S. K., Chukwudi, A. C., Daramola, O. A., Ajufo, U.E., 2008: Evidence of environmental pollution in caprine brains obtained from a relatively unindustrialized area in Nigeria. AJBR, 11, 305-309.

21. International Agency for Research on Cancer (IARC) 2006: IARC monographs on the evaluation of carcinogenic risks to humans. Cobalt in hard-metals and cobalt sulphate, gallium arsenide, indium phosphide and vanadium pentoxide. Lyon. Vol. 86. $1-4$.

22. Kadafa, A. A., 2012: Oil exploration and spillage in the Niger delta of Nigeria. Civil and Environmental Research, 2, 38-51.

23. Klein, S. M., Vykoukal, J., Lechler, P., Zeitler, K., Gehmert, S., Schremi, S., Alt, E., Bogdahn, V., Pranti, L., 2012: Noninvasive in vivo assessment of muscle impairment in the $\mathrm{mdx}$ mouse model-a comparison of two common wire hanging methods with two different results. J. Neurosci. Methods, 203, 292-297.

24. Li, H., Zhou, D., Zhang, Q., Feng, C., Zheng, W., He, K., Lan, Y., 2013: Vanadium exposure induced neurobehavioral alterations among Chinese workers. Neurotoxicity, 36, 49-54.

25. McNeilly, J.D., Heal, M.R., Beverland, I. J., Howe, A., Gibson, M.D., Hibbs, L. R. et al., 2004: Soluble transition metals cause the pro-inflammatory effects of welding fumes in vitro. Toxicol. Appl. Pharmacol., 196, 95-107.

26. Moffett, J.R., Ross, B., Arun, P., Madhavarao, C. N., Namboodiri, M. A. A., 2007: N-acetylaspartate in the CNS: From neurodiagnostics to neurobiology. Prog. Neurobiol., 81, 89-131.

27. Morton, J. F., 1997: Phalsa, Fruits of Warm Climate. Julia Morton, Miami, Florida, 276-277.

28. Mundhe, K. S., Kale, A. A., Gaikwad, S. A., Deshpande, N.R., Kashalkar, R.V., 2011: Evaluation of phenol, flavonoid 
contents and antioxidant activity of Polyalthia longifolia. Journal of Chemical and Pharmaceutical Research, 3, 764-769.

29. Mustapha, O., Oke, O., Offen, N., Siren, A., Olopade, J., 2014: Neurobehavioral and cytotoxic effects of vanadium during oligodendrocyte maturation: A protective role for erythropoietin. Environ. Toxicol. Pharmacol., 38, 98-111.

30. Nicolas, A., Gillet, J. P., Fialip, J., Coudore, F., 2003: An animal model of nociceptive peripheral neuropathy following repeated cisplatin injections. Expl. Neurol., 182, 12-20.

31. Nigeria Bureau of Statistics (NBS) 2014: Nigeria living Standard Survey 2003. First round DDI-NGA-NBS-NLSS2003-v1.2, published by Nigeria Bureau of Statistics, 23 pp.

32. Olopade, J. O., Fatola, I. O., Olopade, F. E., 2011: Vertical administration of vanadium through lactation induces behavioural and neuromorphological changes: Protective role of vitamin E. Nigerian Journal of Physiological Sciences, 26, 55-60.

33. Olssona A.S., Nevison, C.M., Patterson-Kanec, E. G., Sherwind, C. M., Van de Weerde, A.H., Wurbelf, H., 2007: Understanding behaviour: the relevance of ethological approaches in laboratory animal science. Applied Animal Behaviour Science, 81, 245-264.

34. Onwuliri, F. C., Mawak, J.D., Wonang, D. L., Onwuliri, E. A., 2006: Phytochemical, toxicological and Histopathological studies of some medicinal plants in Nigeria. International Journal of Natural and Applied Sciences, 2, 225-229.

35. Pfau, W., Skog, K., 2004: Exposure to beta-carbolines norharman and harman. J. Chromatogr. B., 802, 115-118.

36. Rajamurugan, R., Deepa, V., Sivashanmugam, M., Raghavan, C.M., 2013: Phytochemistry, antioxidant and antibacterial activities of medicinal plants: A comparative Study, IJCRR, 5, 8-19.

37. Reut, A., Elkan, T., Dror, A., Shefer, S., Eilam, D., Avraham, K., Mintz, M., 2009: Mice with vestibular deficiency display hyperactivity, disorientation, and signs of anxiety. Behav. Brain Res., 202, 210-217.

38. Sánchez, D. J., Ortega, A., Domingo, J.L., Corbella, J., 1991: Developmental toxicity evaluation of orthovanadate in the mouse. Biol. Trace Elem. Res., 30, 219-226.
39. Saxena, P.N., Arya, J., Saxena, N., Shukla, A., 2013: Vanadium Intoxication in albino rat based on haematobiochemistry and behaviouristic changes. International Journal of Environmental Engineering and Management, 4, 293-300.

40. Seibenhener, M.L., Wooten, M.C., 2015: Use of the Open Field Maze to measure locomotor and anxiety-like behaviour in mice. Journal of Visualized Experiments, 10, 96-104.

41. Siegel, S., 1956: Nonparametric Statistics for the Behavioral Sciences. McGraw-Hill Inc., 11.

42. Soazo, M., Garcia, G.B., 2007: Vanadium exposure through lactation produces behavioural alterations and CNS myelin deficit in neonatal rats. Neurotoxicol. Teratol., 29, 503-510.

43. Todorich, B., Olopade, J. O., Surguladze, N., Zhang, X., Neely, E., Connor, J.R., 2011: The mechanism of vanadium-mediated developmental hypomyelination is related to destruction of oligodendrocyte progenitors through a relationship with ferritin and iron. Neurotoxicity Res., 19, 361-373.

44. Twumasi, Y., Merem, E., 2006: GIS and remote sensing applications in the assessment of change within a coastal environment in the Niger delta region of Nigeria. International Journal of Environmental Research and Public Health, 3, 98-106.

45. Van Putten, M., Kumar, D., Hulsker, M., Hoogaars, W.M., Plomp, J. J., Van Opstal, A. et al. 2012: Comparison of skeletal muscle pathology and motor function of dystrophin and utrophin deficient mouse strains. Neuromuscular Disord., 22, 406-417.

46. Venkataraman, B. V., Sudha, S., 2005: Vanadium Toxicity. Asian Journal of Experimental Sciences, 19, 127-134.

47. Villers, A., Ris, L., 2013: Improved preparation and preservation of hippocampal mouse slices for a very stable and reproducible recording of long-term potentiation. Journal of Visualized Experiments, 10, 76-83.

Received, June 1, 2016

Accepted, August 25, 2016 